\title{
Dehalogenase producing bacteria from extreme environment: A review
}

\author{
Siti Nurul Fasehah Ismail ${ }^{1}$, Arman Shah², Mohamed Faraj Edbeib ${ }^{3}$, Aliyu Adamu1, ${ }^{1,}$, Firdausi Aliyu ${ }^{1}$, Roswanira Abdul \\ Wahab $^{4 *}$ and Fahrul Huyop ${ }^{1 *}$ \\ ${ }^{1}$ Department of Biotechnology and Medical Engineering, Faculty of Biosciences and Medical Engineering, Universiti \\ Teknologi Malaysia, 81310 Johor, Malaysia. \\ ${ }^{2}$ Department of Engineering Technology, Faculty of Technical and Vocational Education, Universiti Pendidikan Sultan \\ Idris, 35900 Tanjong Malim, Perak, Malaysia. \\ ${ }^{3}$ Department of Animal Production, Faculty of Agriculture, Bani Walid University, Bani Walid, Libya. \\ ${ }^{4}$ Department of Chemistry, Faculty of Science, Universiti Teknologi Malaysia, 81310 Johor, Malaysia. \\ ${ }^{5}$ Department of Microbiology, Faculty of Science, Kaduna State University, Tafawa Balewa way, Kaduna PMB 2339 , \\ Nigeria. \\ Email: roswanira@kimia.fs.utm.my; fahrul@utm.my
}

Received 22 August 2017; Received in revised form 22 May 2018; Accepted 4 June 2018

\begin{abstract}
Halogenated compounds create the most important class of xenobiotic which commonly lead to pollution. Some of these compounds are very toxic and cause enormous problems to human health and to the environment. Many of these toxic chemicals have been shown to occur in various extreme habitats. Pollutant-degrading microorganisms, adapted to grow in various environments, play an important role in the biological treatment of polluted extreme habitats. The presence of dehalogenase producing microorganisms in extreme habitat in particular is necessary since the enzyme can catalyze the removal of a halogen atom from a substrate. Therefore, it can reduce the toxicity of the halogenated compound and some are of interest for study in industrial application. Thermophiles, psychrophiles, acidophiles, alkaliphiles and halophiles are types of extremophiles. Knowledge of the biodegradation of toxic chemicals in extreme environment is limited. Here, examples of dehalogenase producing bacteria isolated from various extreme conditions and its special characteristics/features will be discussed in this review.
\end{abstract}

Keywords: halogenated compound, extremophiles, dehalogenase, environment

\section{INTRODUCTION}

Halogenated hydrocarbons are commonly found in environment due to their extensive use in industry and agriculture as insecticides, herbicides, solvents and intermediates for chemical syntheses. Halogenated compounds are toxic and persistence thus cause environmental pollution and human health problems (Chaudhry and Chapalamadugu, 1991). Dehalogenase are enzymes that catalyse the removal of a halogen atom from halogenated compounds. Microbial dehalogenases detoxify harmful halogenated compounds by cleaving carbon-halogen bonds in such compounds (Copley, 1998; Kurihara et al., 2000). These enzymes are important for bioremediation of environmental pollution caused by halogenated hydrocarbon pollution, which are synthetically produced as herbicides and growth regulators (Allpress and Gowland, 1998).

Extremophiles are organisms that tolerate extreme environmental conditions such as high temperature, pressure, salt concentrations as well as low temperature, $\mathrm{pH}$, nutrient concentrations and water availability. High level of radiation, harmful heavy metals and toxic compounds also are categorized as extreme environment. The normal microbial conditions for growth and reproduction include temperature of between $20^{\circ} \mathrm{C}$ to 40 ${ }^{\circ} \mathrm{C}, \mathrm{pH}$ value is near neutral, air pressure of about 1 atm and sufficient amount of water of activity (Satyanarayana et al., 2005). Because microorganisms have broader tolerable range of environmental conditions, extremophiles are mostly found among microbes. Some microorganisms can grow and reproduce at between -12 ${ }^{\circ} \mathrm{C}$ to $>100{ }^{\circ} \mathrm{C}, \mathrm{pH} 0$ to 13 , saturated brine and pressure of up to $1400 \mathrm{~atm}$. Extremophilic organisms do not only tolerate but also require extreme conditions to survive. It can develop its whole life cycle in these conditions. Extremophilic organisms are mainly prokaryotes (archaea and bacteria), with few eukaryotes (López-García, 2005). 
Depending on the extreme conditions, extremophiles are of various types, which include: thermophiles (extreme heat), psychrophiles (extreme cold), alkaliphiles (high $\mathrm{pH}$ levels), acidophiles (low pH levels) and halophiles (extreme saltiness).

It is important to investigate dehalogenase from extreme environment. Usually, mesophilic organisms have been used to obtain enzymes of interest due to its advantages. However, the application of these enzymes are restricted by their stability in mesophic environments (Kumar et al., 2011). Potential applicatons of such enzymes are not restricted to mesophic condition. Therefore, investigation of dehalogenase from extreme environment is very important, so as to allow their application beyound normal environmental conditions. For example, the enzymes isolated from thermophilic organisms regularly show stability to several extrinsic factors such as temperature and organic solvents. These properties make them particularly useful for application as industrial biocatalyst (Rye et al., 2009).

Extremophiles are source of enzymes (extremozymes) with extreme stability; and the application of these enzymes as biocatalysts is attractive because they are stable and active under conditions that were previously regarded as incompatible with biological materials. Furthermore, some extremophiles, particularly those from the Archaea, have novel metabolic pathways and thus can serve as a source of enzymes with novel activities and applications (Kumar et al., 2011). Over the last few decades, extremophiles have attracted the attention of researcher in the search for new bioactive substances, such as enzymes and biocides to be used in major sectors of the world economy, including the agricultural, chemical, food, textile, pharmaceutical, bioenergy and cosmetic industries (Dalmaso et al., 2015). Current review will focus on how these micoorganisms can survive at extreme environments and some of them produce dehalogenase enzymes that have the ability to remove the halogenated compound from severe environments.

\section{DEHALOGENASE PRODUCING BACTERIA ISOLATED FROM EXTREME ENVIRONMENT}

\section{Thermophiles}

Thermophiles can be divided into 3 groups such as moderate thermophile (growth optimum 50-60 ${ }^{\circ} \mathrm{C}$ ), extreme thermophile (growth optimum $60-80{ }^{\circ} \mathrm{C}$ ) and hyperthermophile (growth optimum $80-110{ }^{\circ} \mathrm{C}$ ) (Kumar et al., 2011). Many investigations focused on their potential as sources of highly active enzymes 'extremozymes' (Aanniz et al., 2015). Thermophilic microorganisms can be isolated from virtually any environment that receives intermittent heat, such as soil and compost. Hyperthermophiles thrive only in a very hot and constantly hot environments, including hot springs, both terrestrial and undersea (hydrothermal vents), and active sea mounts, where volcanic lava is emitted directly onto the sea floor (Raven and Johnson, 2001). Thermophilic bacteria grow at very high temperatures and have a variety of properties and specialisations that allow their cells and molecules to remain functional at high temperatures. For an organism to grow at high temperatures, all cellular components, including proteins, nucleic acids, and lipids, must be heat stable. The structural features that dictate thermal stability in proteins are not well understood but a small number of noncovalent features seem characteristic of thermostable proteins. These include a highly a polar core, which undoubtedly makes the inside of the protein "sticky" and thus more resistant to unfolding, a small surface-tovolume ratio, which confers a compact form on the protein, a reduction in glycine content that tends to remove options for flexibility and thus introduce rigidity to the molecule, and extensive ionic bonding across the protein's surface that helps the compacted protein resist unfolding at high temperature. In addition to these intrinsic stability factors special proteins called chaperonins are synthesized by hyperthermophiles. Chaperonins functions to bind heat denatured proteins and refold them into their active form (Raven and Johnson, 2001).

Dalmaso et al. (2015), described that thermophiles have several mechanisms to support extreme temperatures. It is believed that the thermostability of cellular components such as ATP, amino acids, and peptides may exceed $250{ }^{\circ} \mathrm{C}$, suggesting that the maximum temperature for life goes beyond the temperatures that have been observed until now. The proteins of organisms adapted to extreme temperatures generally have similar three-dimensional structures of mesophilic organisms but the amino acid content is different from ordinary proteins and the number of charged residues on their surfaces is much greater than non-adapted organisms. In addition, such proteins often have shorter loops, thus preventing the occurrence of nonspecific interactions due to their increased flexibility at high temperatures. Extreme thermophilic bacteria produce thermostable proteins that can be readily crystallized to obtain stable enzymes for structural and functional studies. Proteins from hyper/thermophiles require sufficient structural rigidity to resist unfolding. This is an important feature to characterize antidrug targets. A classical instance is the bacteria Thermus thermophilus that was originally isolated from a thermal vent within a hot spring in Izu, Japan, and is frequently used in genetic manipulation studies. The DNA gyrase from this extremophile has been used as an antidrug target model. DNA gyrase is a type IIA topoisomerase that introduces negative supercoils into closed circular bacterial DNA using ATP hydrolysis. It is an important antibacterial target that is sensitive to the widely-used fluoroquinolone drugs (Dalmaso et al., 2015).

Moreover, the thermal hypothesis determines that a G:C pair and its contents are related to thermostability. This is observed for several thermophilic bacteria. Geobacillus thermoleovorans CCB US3UF5 is a thermophilic bacterium that was isolated from a hot spring in Malaysia and is a source for thermostable enzymes. The bacteria contains a circular chromosome of $3,596,620$ bp with a mean G:C content of $52.3 \%$ (Sakaff et al., 
2012). However, a study reported thecomparative analyses of G:C composition and optimal growth temperature with 100 prokaryote genomes (Archaea and Bacteria domains) that failed to demonstrate this correlation (G:C/thermostability). Moreover, the $\mathrm{G}: \mathrm{C}$ content of structural RNA (16S and 23S) is strongly correlated with optimal temperature and it is higher at high temperatures (Hurst and Merchant, 2001). An increased number of disulfide bonds improves stability within thermophilic proteins and play a role in preventing the alteration of the quaternary structure (Reed et al., 2013).

Another specialization of thermophiles is membrane stability. Heat can also affect membrane stability. In organisms living at moderate temperatures cell membranes are constructed along the typical "lipid bilayer" model: hydrophobic residues (fatty acids) inside oppose each other and retain an affinity for one another while hydrophilic residues (glycerol phosphate) lie at the surface of the environment and the cytoplasm, respectively, maintaining contact with the aqueous phase. If one applies sufficient heat to such membrane architecture the two leaflets of the membrane will pull apart, leading to membrane damage and cytoplasmic leakage. To prevent this from occurring at very high temperatures, hyperthermophiles have evolved a novel membrane structure. Instead of forming a membrane as a lipid bilayer, hyperthermophiles chemically bond the opposing hydrophobic residues from each layer of the membrane together. This forms a lipid monolayer instead of a bilayer, and prevents the membrane from melting at high temperature. Although the precise chemistry of lipid monolayer membranes can vary somewhat from species to species, they are universal among hyperthermophiles and are undoubtedly an evolutionary response to life at high temperature (Raven and Johnson, 2001).

Table 1 shows the thermophilic organism that can produce dehalogenase. Smith et al. (1989) extracted HadD enzyme from Pseudomonas putida strain AJ1/23. They found that the highest temperature in which HadD enzyme can maintain it activity was $50^{\circ} \mathrm{C}$. Nonetheless, it was inactivated at higher temperatures. Diez et al. (1996) studied L-2-haloacid dehalogenase from Azotabacter sp. strain RC26. The temperatures ranged from 30 to $60^{\circ} \mathrm{C}$ for active enzyme activities. Jesenská et al. (2002) isolated Mycobacterium avium subsp. Avium N85 from swine mesenteric lymph nodes. The dehalogenase gene found in Mycobacterium avium subsp. Avium N85 was called $d h m A$. Temperature from 20 to $50^{\circ} \mathrm{C}$ exhibited the increasing of dehalogenase activity. The highest activity was detected at $50^{\circ} \mathrm{C}$.

Bachas-Daunert et al. (2009) identified a putative dehalogenase, L-HADst, derived from the thermophile Sulfolobus tokodaii. L-HADst was incubated for $4 \mathrm{~h}$ at 70 ${ }^{\circ} \mathrm{C}$ showed fully active and stands at extreme $\mathrm{pH}$ conditions ranging from 4 to 10 . Rye et al. (2009) studied L-2-haloacid dehalogenase from the thermophilic archaeon Sulfolobus tokodaii. The enzyme shows haloacid dehalogenase activity towards carboxylic acids with the halide attached at the carbon 2 (C2) position with the maximum activity towards chloropropionic acid. At 60
${ }^{\circ} \mathrm{C}$ the enzyme displays maximum activity but the enzyme had a half-life over $1 \mathrm{~h}$ at $70^{\circ} \mathrm{C}$.

Thasif et al. (2009), isolated a thermostable L-specific dehalogenase (DehL) from cells of Pseudomonas sp. strain S3. DehL still shows enzyme stability even at $55^{\circ} \mathrm{C}$. Godinho and de Sá-Nogueira (2011) studied a member of the ubiquitous haloalkanoate dehalogenase superfamily that is AraL from Bacillus subtilis. The temperatures used for AraL's activity, ranging from 25 to $70^{\circ} \mathrm{C}$.

Novak et al. (2013a) isolated L-haloacid dehalogenase from the marine bacterium Psychromonas ingrahamii. It displays activity towards monobromoacetic (100\%), monochloroacetic acid (62\%), S-chloropropionic acid (42\%), S-bromopropionic acid (31\%), dichloroacetic acid $(28 \%)$ and 2-chlorobutyric acid (10\%). The substrates with shorter carbon chain lengths, exhibited the highest activity of L-haloacid dehalogenase. The optimal temperature for activity was at $45^{\circ} \mathrm{C}$ and retains above $70 \%$ of its activity after incubated at $65^{\circ} \mathrm{C}$ for 90 min. Novak et al. (2013b) established the putative L-haloacid dehalogenase gene (DehRhb) from a marine Rhodobacteraceae. The DehRhb protein was revealed to be an L-haloacid dehalogenase with highest activity on brominated substrates. The optimal temperature for enzyme activity was $55^{\circ} \mathrm{C}$ with a melting temperature of $67^{\circ} \mathrm{C}$. After incubation at $50{ }^{\circ} \mathrm{C}$ for $90 \mathrm{~min}$, the enzyme showed $85 \%$ of its activity.

$\mathrm{Li}$ and Shao (2014) reported that Alcanivorax dieseloleistrain B-5 strain from marine environment was capable of degrading halogenated alkanes. The putative haloalkane dehalogenase (HLD) produced by Alcanivorax dieseloleistrain B-5 named DadB. The optimum temperature of this strain was $50{ }^{\circ} \mathrm{C}$ but severely lost activity at $60^{\circ} \mathrm{C}$.

In addition, there are some examples of dehalogenase producing bacteria isolated from thermophilic area in which the isolates were not reported to survive within a temperature range of 50 to $110^{\circ} \mathrm{C}$. As an example, Hamid et al. (2010), isolated unknown strain AZZ2 from extreme environment that was from volcanic area Gunung Sibayak, Indonesia. This unknown strain AZZ2 was cultured in 2,2-dichloropropionic acid as sole source of carbon and energy at $30^{\circ} \mathrm{C}$. Based on molecular analysis, strains $A Z Z 2$ has the highest sequence similarity to Citrobacter sp. JC73/SL7. Hence, it was designated as Citrobacter sp. strain AZZ2. Moreover, Roslan et al. (2011), isolated Bacillus megaterium GS1 from thermophilic area that is from volcanic area Gunung Sibayak. They aimed to investigate 2,2-dichloropropionic acid $(2,2-\mathrm{DCP})$ degrading bacteria that can grow at higher temperature rather than at normal 25 to $30^{\circ} \mathrm{C}$ temperature. Therefore, the culture was incubated for 2 days at 30,40 and $60^{\circ} \mathrm{C}$ incubator shaker aerobically. Thus, it was resulted that the isolated bacterium grew best at $40{ }^{\circ} \mathrm{C}$ but failed to grow at $60^{\circ} \mathrm{C}$. Salim et al. (2011) also isolated bacteria from volcanic area Gunung Sibayak, Bacillus megaterium GS1. It could grow on various concentrations of 2,2-DCP up to $40 \mathrm{mM}$. A putative partial dehalogenase DehGS1 amino acid sequence was proposed from Bacillus megaterium GS1 catalyzed 2,2DCP. 
Malays. J. Microbiol. Vol 14(5) 2018, pp. 424-434

DOI: http://dx.doi.org/10.21161/mjm.113217

Table 1: Dehalogenase producing organisms isolated from thermophilic environment.

\begin{tabular}{llll}
\hline Environmental Factor & Organisms & Temperature & Reference \\
\hline High Temperature & Pseudomonas putida strain AJ1/23 & $50^{\circ} \mathrm{C}$ (moderate thermophile) & Smith et al. (1989) \\
(Thermophile) & Azotabacter sp. strain RC26 & $60^{\circ} \mathrm{C}$ (hyperthermophile) & Diez et al. (1996) \\
& Mycobacterium avium & $50^{\circ} \mathrm{C}$ (moderate thermophile) & Jesenská et al. (2002) \\
& Sulfolobus tokodaii & $70^{\circ} \mathrm{C}$ (hyperthermophile) & Bachas-Daunert et al. (2009) \\
& Sulfolobus tokodaii & $70^{\circ} \mathrm{C}$ (hyperthermophile) & Rye et al. (2009) \\
& Pseudomonas sp. strain S3 & 50 to $55^{\circ} \mathrm{C}$ (moderate thermophile) & Thasif et al. (2009) \\
& Bacillus subtilis & $65^{\circ} \mathrm{C}$ (hyperthermophile) & Godinho and de Sá-Nogueira (2011) \\
& Psychromonas ingrahamii & $65^{\circ} \mathrm{C}$ (hyperthermophile) & Novak et al. (2013a) \\
& Rhodobacteraceae. & $55^{\circ} \mathrm{C}$ (moderate thermophile) & Novak et al. (2013b) \\
& Alcanivorax dieseloleistrain B-5 & $50^{\circ} \mathrm{C}$ (moderate thermophile) & Li and Shao (2014) \\
\hline
\end{tabular}

Table 2: Dehalogenase producing organisms isolated from psychrophilic environment.

\begin{tabular}{llll}
\hline Environmental Factor & Organisms & Temperature & Reference \\
\hline Low temperature & Psychrobacter cryohalolentis K5 & $-10{ }^{\circ} \mathrm{C}$ & Bakermans et al. (2003) \\
(Psychrophile) & Psychrobacter cryopegella & -10 to $28{ }^{\circ} \mathrm{C}$ & Bakermans and Nealson (2004) \\
& Psychrobacter cryohalolentis K5 & $5^{\circ} \mathrm{C}$ & Drienovska et al. (2012) \\
\hline
\end{tabular}




\section{Psychrophiles}

Psychrophiles (cryophiles) also known as cold-loving are extremophiles organisms that can grow and reproduce in cold temperatures of less than $15^{\circ} \mathrm{C}$ (van den Burg, 2003). Psychrophilic microorganisms have successfully colonised all permanently cold environments from the deep sea to the mountain and polar regions (Morita, 1975). This unique property implies that psychrophiles have successfully overcome two main challenges such as low temperature, because any decrease in temperature exponentially affects the rate of biochemical reactions and the viscosity of aqueous environments, which increases by a factor higher than two between $37^{\circ} \mathrm{C}$ and $0{ }^{\circ} \mathrm{C}(\mathrm{Xu}$ et al., 2003).

Among the bacteria that have been detected, the most commonly reported microorganisms are the Gramnegative $\alpha-, \beta$ - and $\gamma$-proteobacteria (Pseudomonas spp. and Vibrio spp.) and the Cytophaga-FlavobacteriumBacteriodes phylum. Coryneforms, Arthrobacter sp. and Micrococcus sp. are the most frequently found Grampositive bacteria. Bacteria generally dominate in some areas such as deepsea waters are Methanogenium and Methanococcus being the most cited genera (Pandey et al., 2004).

There are several properties of psycrophiles able to thrive at extreme conditions such as membrane fluidity, transcription and translation, antifreeze proteins and cryoprotectants and cold-adapted enzymes. Decreasing temperatures have an adverse effect on the physical properties and functions of membranes, typically leading to a reduction in membrane fluidity, the onset of a gelphase transition and, ultimately, a loss of function. The lipid composition governs the physical properties of membranes and hence it is not surprising that this varies with the thermal habitat of the microorganism. In general, lower growth temperatures produce a higher content of unsaturated, polyunsaturated and methyl-branched fatty acids, and/or a shorter acyl-chain length, with studies reporting a high proportion of cis-unsaturated doublebonds and antesio-branched fatty acids (Chintalapati et al., 2004; Russell, 1997). This altered composition is thought to have a key role in increasing membrane fluidity by introducing steric constraints that change the packing order or reduce the number of interactions in the membrane. Further adaptations that have been suggested to increase membrane fluidity include an increased content of large lipid head groups, proteins and non-polar carotenoid pigments (Chintalapati et al., 2004).

Some of the main barriers to protein synthesis at low temperatures include: reduced activity of transcriptional and translational enzymes; reduced protein folding, owing primarily to a reduced rate of prolyl isomerization; and a stabilization of DNA and RNA secondary structures. In psychrophiles, enzymes involved in these processes have adapted to be optimally active at low temperatures. For example, a ribosomal extract, RNA polymerase, elongation factor and peptidyl-prolyl cis-trans isomerase have all been shown to retain activity near $0^{\circ} \mathrm{C}$ in several psychrophilic microorganisms. Indeed, these latter enzyme catalyses cis-trans prolyl isomerizations, and its high activity and overexpression at low temperatures might be important for maintaining protein-folding rates at low temperatures. Furthermore, nucleic-acid-binding proteins for example, Escherichia coli CspA-related proteins and RNA helicases that might be important for the destabilization of DNA and RNA secondary structures are also overexpressed at low temperatures in psychrophiles (Berger et al., 1996; Lim et al., 2000).

Antifreeze proteins (AFPs) can bind to ice crystals through a large complementary surface and thereby create thermal hysteresis and lower the temperature at which an organism can grow (Jia and Davies, 2002). AFPs have been recently demonstrated in Antarctic lake bacteria (Gilbert et al., 2004), one of which, from Marinomonas primoryensis, is $\mathrm{Ca}^{2+-}$ dependent and hyperactive (Gilbert et al., 2005). The AFP from the Arctic plant growth-promoting rhizobacterium Pseudomonas putida GR12-2 shows both antifreeze and ice-nucleating activities (Muryoi et al., 2004). Trehalose and exopolysaccharides (EPSs) might also have an important role in cryoprotection in psychrophiles. Trehalose is thought to have a colligative effect, but probably also helps in preventing protein denaturation and aggregation (Phadtare, 2004). The modification of physico-chemical environment of bacterial cells, participate in cell adhesion to surfaces and retention of water, favour the sequestration and concentration of nutrients, retain and protect extracellular enzymes against cold denaturation and act as cyoprotectants (Nichols et al., 2005). Riley et al. (2008) studied whether the sizes of proteins of a psychrophile differ from those of a mesophile. The sequences of all proteins of Psychromonas ingrahamii were compared to sequences of all proteins of three other bacteria such as Shewanella oneidensis MR-1, Vibrio cholerae and Escherichia coli K-12 MG1655 and 916 protein sequences were conserved among all four bacteria. Most of the conserved amino acids were enzymes $P$. ingrahamii contains proteins with relatively high asparagine content, and low content of amino acids potentially sensitive to the higher concentration of oxygen present in cold waters. These properties would seem to be appropriate for an extreme psychrophiles.

Psychrophiles produce cold-adapted enzymes that have high specific activities at low temperatures, often up to an order of magnitude higher than those observed for their mesophilic counterparts. Psychrophilic enzymes increase the flexibility of their structure to compensate for the 'freezing effect' of cold habitats (Johns and Somero, 2004).

There are some examples of dehalogenase psychrophilic organisms and the low temperature which they can thrive (Table 2). Bakermans et al. (2003), discovered microorganism from saline-water lenses found from 40,000-year-old Siberian permafrost named Psychrobacter cryohalolentis K5. P. cryohalolentis was nominated for genome sequencing for its capability to reproduce at $-10^{\circ} \mathrm{C}$ with a generation time of 39 days and rapid growth at low temperature. Bakermans and Nealson (2004) identified Psychrobacter cryopegella isolated from 
a briny water lens inside Siberian permafrost, where the temperature is $-12{ }^{\circ} \mathrm{C}$. P. cryopegella could reproduce at temperature from $-10{ }^{\circ} \mathrm{C}$ to $28^{\circ} \mathrm{C}$, with its maximum growth rate at $22{ }^{\circ} \mathrm{C}$.

Drienovska et al. (2012) studied a haloalkane dehalogenase, DpcA, from Psychrobacter cryohalolentis K5. It represents a novel psychrophilic member of the haloalkane dehalogenase family. The temperature ranges from $5{ }^{\circ} \mathrm{C}$ to $35^{\circ} \mathrm{C}$ were experimented for temperature profile of DpcA. The highest activity of the enzyme was detected at $25{ }^{\circ} \mathrm{C}$ and retained almost $27 \%$ of its maximal activity at $5^{\circ} \mathrm{C}$.

The studies on the isolation of bacteria from psychrophilic environment that is marine sponge Hymeniacidon perlevis were done by Huang et al. (2010) and Huang et al. (2011). Sponge was a good source for the dehalogenase producing bacteria isolation as reported by Huang et al. (2010). The sponge $H$. perlevis inhabits the estuarine intertidal area of the Chinese Yellow Sea. The optimal growth temperature of the marine sponge in its natural habitat is ranging $8-18{ }^{\circ} \mathrm{C}$. Huang et al. (2011) reported that bacteria isolated from marine sponge could degrade 2-chloropropionic acid (2-CPA). However, they did not study the ability of bacteria from marine sponge to survive at psycrophilic temperature.

\section{Alkaliphiles / Acidophiles}

The term alkaliphilic microorganisms or "alkaliphiles," generally refers to microorganisms that grow well at $\mathrm{pH}$ values exceeding $\mathrm{pH} 9$ or between $\mathrm{pH} 10$ to 13 . Alkaliphiles can be found at neutral environments, acidic soil and feces (Horikoshi, 1999). Enzymes produced by microorganisms from extreme $\mathrm{pH}$ will be useful for applications under highly acidic or highly alkaline, for example in the production of detergents (van den Burg, 2003). Microorganisms growing in highly acidic environments ( $\mathrm{pH}$ values below 3) are found in all three domains of life such as Archaea, Bacteria and Eucarya (López-García, 2005). Acidophiles can withstand and even thrive in acidic environments at $\mathrm{pH}$ below 5 . Acidophiles can be found in acidic environments, including sulfuric ponds, geysers, or polluted acid mine drainage, and our own stomach. Acidophilic prokaryotes involved in the industrial leaching of copper and other metals from ores.

Alkaliphiles and acidophiles have unique properties that make them survive in extreme $\mathrm{pH}$. One of the striking properties of alkaliphilic and acidophilic microorganisms is their ability to maintain a neutral pH internally, and so the intracellular enzymes from these microorganisms do not need to be adapted to extreme growth conditions. If cells are to survive in an alkaline environment, they must make their cytoplasm more acidic to buffer the alkalinity. Acidophilic and alkaliphilic microorganisms use their proton pumps to maintain a neutral $\mathrm{pH}$ internally and so the intracellular enzymes from these microorganisms do not need to be adapted to extreme growth conditions. However, the extracellular enzymes of acidophiles have to function at low $\mathrm{pH}$ whereas those of alkaliphiles function at alkaline $\mathrm{pH}$ (Kumar et al., 2011). For the cells to survive in the aggressive conditions of $\mathrm{pH}$, alkaliphiles and acidophiles develop other systems as well. Alkaliphiles have negatively charged cell wall polymers apart from peptidoglycan which may reduce the charge density at the cell surface and help to stabilize the cell membrane. Cellular fatty acids in alkaliphilic bacterial strains contain predominantly saturated and mono-unsaturated straightchain fatty acids. For acidophiles employ a range of mechanisms to withstand low $\mathrm{pH}$ such as a positively charged membrane surface a high internal buffer capacity, over-expression of $\mathrm{H}^{+}$exporting enzymes and unique transport systems (Horikoshi, 1999).

A major contribution of alkaliphiles to enzymes used in industry is the diversity of enzymes with activity optima shifted to the alkaline $\mathrm{pH}$ region. Examples of alkaliphile enzymes and their uses include alkaline proteases, which are used as detergent additives and for removing hair from hides; starch-degrading amylases with elevated $\mathrm{pH}$ optima are also suitable for laundry use and debranching enzymes, together with amylase, play a role in stain removal (Preiss et al., 2015). Enzymes produced by acidophiles such as amylases, glucoamylases, proteases, cellulases and oxidases are used for starch processing, feed component and desulfurization of coal (van den Burg, 2003).

Alkaliphiles and acidophiles also produced dehalogenase enzyme. Table 3 summarized the $\mathrm{pH}$ of alkaliphilic dehalogenase and acidophilic organisms that they can survive in both conditions. Pseudomonas putida strain AJ1/23 produces HadD enzyme and able to withstand pH 9.5 (Smith et al., 1989). Smith et al. (1990) isolated D-2-haloacid dehalogenase from Pseudomonas putida strain AJ1/23. The maximum enzyme activity ariseat $\mathrm{pH} 9.5$ and $50{ }^{\circ} \mathrm{C}$. Significant enzyme activity only happened in alkaline conditions which is dependable with the nature of the reaction mechanism. The enzyme activity lost below $\mathrm{pH} 5$. The enzyme was stable at $\mathrm{pH}$ range from $\mathrm{pH}$ 6-9, and became fewer in strongly alkaline conditions. Hasan et al. (1994) studied the activity of Pseudomonas on D,L-2-chloropropionate (D,L-2CP) and 2-chloroacrylate (2-CAA). At pH 9.5 the maximum activity of $\mathrm{D}, \mathrm{L}-2 \mathrm{CP}$ and $\mathrm{pH} 10$ showed the maximum activities of the 2-CAA-induced enzymes.

A bacterium Rhodococcus sp. capable of utilizing 3chloropropionic acid as a sole carbon source was isolated from Universiti Teknologi Malaysia agricultural soil area. Activity of the enzyme was measured by determining the release of chloride indicated by a colorimetric method employing mercuric thiocyanate. The dehalogenase enzyme was preceded rapidly at pH 6.0 and 9.0 (Jing and Huyop, 2007).

A Pseudomonas sp. strain S3, which can utilise a halogenated compound of $\mathrm{D}, \mathrm{L}-2 \mathrm{CP}$ as sole carbon and energy source. The maximum activity of $D$-specific dehalogenase (DehD) enzyme on $\mathrm{D}-2 \mathrm{CP}$ was found at $\mathrm{pH}$ 9.5 at $35{ }^{\circ} \mathrm{C}$. Pseudomonas sp. strain S3, which can utilize a halogenated compound of D, L-2CP as a carbon was also isolated. The maximum activity of $\mathrm{D}$-specific dehalogenase enzyme was established at pH 9.5 (Thasif 
Malays. J. Microbiol. Vol 14(5) 2018, pp. 424-434

DOI: http://dx.doi.org/10.21161/mjm.113217

Table 3: Dehalogenase producing organisms from alkaliphiles and acidophiles conditions.

\begin{tabular}{llll}
\hline Environmental Factors & Organism & $\mathrm{pH}$ & Reference \\
\hline & Pseudomonas putida strain AJ1/23 & 9.5 & Smith et al. (1989) \\
& Pseudomonas putida strain AJ1/23 & 6 to 9 & Smith et al. (1990) \\
& Pseudomonas & 9.5 to 10 & Hasan et al. (1994) \\
& Rhodococcus sp. & 9 & Jing and Huyop (2007) \\
& Pseudomonas sp. strain S3 & 9.5 & Thasif et al. (2009) \\
& Agrobacterium tumefaciens C58 & 9.8 & Hasan et al. (2011) \\
& Paracoccus sp. DEH99 & 10 & Zhang et al. (2014) \\
& Sulfolobus tokodaii & 4 to 10 & Bachas-Daunert et al. (2009) \\
& Pseudomonas fluorescens DSM 8341 & 4 to 10 & Donnelly and Murphy (2009) \\
& Alcanivorax dieseloleistrain B-5 & 5.0 to 10.0 & Li and Shao (2014) \\
\hline
\end{tabular}

Table 4: Dehalogenase producing organisms from halophilic conditions.

\begin{tabular}{|c|c|c|c|}
\hline Environmental Factor & Organism & Salinity & References \\
\hline & $\begin{array}{l}\text { Roseobacter sp., Paracoccus homiensis sp., Pseudomonas } \\
\text { putida sp. Pseudomonas stuzeri sp. }\end{array}$ & $15 \%$ & Huang et al. (2011) \\
\hline Extreme salinity (Halophiles) & $\begin{array}{l}\text { Serratia sp. } \\
\text { Raoutella ornithilolytica } \\
\text { Bacillus sp., Rhodococcus sp., Lysinibacillus sp., Microbacterium } \\
\text { sp. and Aminobacter sp. } \\
\text { Gelliodes sp. } \\
\text { Pseudomonas aeruginosa MX1 }\end{array}$ & $\begin{array}{l}1 \% \\
1 \% \\
8 \% \\
-\end{array}$ & $\begin{array}{l}\text { Abel et al. (2012) } \\
\text { Niknam et al. (2014) } \\
\text { Khosrowabadi and Huyop (2014) } \\
\text { Sufian et al. (2015) } \\
\text { Edbeib et al. (2016b) }\end{array}$ \\
\hline
\end{tabular}


et al., 2009). Hasan et al. (2011) discovered a novel haloalkane dehalogenase, DatA that was isolated from the plant pathogen Agrobacterium tumefaciens C58. The effect of $\mathrm{pH}$ on the activity of DatA was examined by using 1, 3-Dibromopropane. The activity was accessed in the range of $\mathrm{pH}$ from 5 to 11 , with the maximal activity at $\mathrm{pH}$ 9.8. Zhang et al. (2014) investigated 2-haloacid dehalogenase, Deh99 purified from Paracoccus sp. DEH99, derived from marine sponge Hymeniacidon perlevis. The optimal $\mathrm{pH}$ for Deh99 activity was $\mathrm{pH} 10.0$.

A putative dehalogenase, L-HADST, identified by Bachas-Daunert et al. (2009) extracted from the thermophile microorganism Sulfolobus tokodaii was able to tolerate extreme $\mathrm{pH}$ conditions ranging from 4 to 10 . Donnelly and Murphy (2009) studied the degradation of fluoroacetate. A Pseudomonas fluorescens DSM 8341 was isolated from soil and the dehalogenase enzyme was purified from cell-free extracts and was characterized. The enzyme was stable between $\mathrm{pH} 4$ and 10. DadB enzyme was obtained from Alcanivorax dieseloleistrain $B-5$. The enzyme was active at low $\mathrm{pH}$ from $\mathrm{pH} 5.0$ to 10.0 . Furthermore, DadB was stable in buffers with $\mathrm{pH}$ above pH 7.5 (Li and Shao, 2014).

\section{Halophiles}

Halophiles can survive in hypersaline habitats by their ability to maintain osmotic balance. They can be found in lakes, oceans, salt pans or salt marshes. They accumulate salts such as sodium or potassium chloride $(\mathrm{NaCl}$ or $\mathrm{KCl})$, up to concentrations that are isotonic with the environment. Proteins from halophiles have to cope with very high salt concentrations such as $\mathrm{KCl}$ concentrations close to $4 \mathrm{M}$ and $\mathrm{NaCl}$ concentrations of $>$ $5 \mathrm{M}$ (Kumar et al., 2011). According to the optimal salt concentration for growth, they are classified in three categories such as extreme halophile (grows in an environment with $3.4-5.1 \mathrm{M}(20 \%$ to $30 \%) \mathrm{NaCl})$, moderate halophile (grows in an environment with 0.85 $3.4 \mathrm{M}(3 \%$ to $25 \%) \mathrm{NaCl}$ ) and slightly halophile (grows in an environment with $0.2-0.85 \mathrm{M}(1 \%$ to $5 \%) \mathrm{NaCl}$ ) (Pikuta et al., 2007). Halotolerant microorganisms do not show an absolute requirement for salt to grow but grow well in high salt concentrations (Siglioccolo et al., 2011). Members of the family Halobacteriaceae have been isolated from different habitats including alkaline and salt lakes, marine salterns, the Dead Sea and saline soils. Some halophiles also are thermostable and tolerant to a wide range of $\mathrm{pH}$ (Dalmaso et al., 2015). In addition, halophilic bacteria can be isolated from many sources such as fish, animal hides, domestic dishwasher, polar ice, spider webs in desert caves and anchovies (Edbeib et al., 2016a).

There are several properties of halophiles to withstand in extreme condition. Halophiles have developed different adaptive strategies to support the osmotic pressure induced by the high $\mathrm{NaCl}$ concentrations in the environments they inhabit. Some extremely halophilic bacteria accumulate inorganic ions $\left(\mathrm{K}^{+}, \mathrm{Na}^{+}, \mathrm{Cl}^{-}\right)$in the cytoplasm, which is a type of "salt-in" strategy to balance the osmotic pressure of the environment, and they have also developed specific proteins that are stable and active in the presence of salts (Dalmaso et al., 2015). The highsalt-in strategy is an adaptation that protects halophiles from a saline environment in which they accumulate inorganic ions intracellularly to balance the salt concentration in their environment. This process involves $\mathrm{Cl}^{-}$pumps that are found only in halophiles that transport $\mathrm{Cl}^{-}$from the environment into the cytoplasm. Arginines and/or lysines are positioned at both ends of the channel to facilitate $\mathrm{Cl}^{-}$uptake and release (Edbeib et al., 2016a). Halophilic organisms contain enzymes that maintain their activity at high salt concentrations, alkaline $\mathrm{pH}$ and high temperatures (Siglioccolo et al., 2011). Most proteins and enzymes denature when suspended in high salt concentrations. It is because, charge balance is important for protein stability, because a protein uses charged residues (as well as other factors) to fold and stay folded. Halophilic proteins bind significant amounts of salt and water. This characteristic is dependent on the number of acidic amino acids on the surface of the protein. The amino acid composition of halophilic enzymes generally contains abundant of acidic amino acid- like aspartic and glutamic acids, a low frequency of lysine, and a high occurrence of amino acids with a low hydrophobic character. Structural analyses between halophilic and mesophilic proteins reveal that the major differences are concentrated on the surface of the protein. These characteristics allow cooperation with electrostatic interactions and the presence of a higher number of salt bridges (Tadeo et al., 2009).

Moreover, one of the halophile adaptation mechanism developed is the lipid composition. Structural adaptations have been observed in the surface layers (S-layers) of halophiles. The extreme halophile contains sulfated glucuronic acid residues and a higher degree of glycosylation, leading to an increased density in surface charges. This characteristic demonstrates an adaptation in response to the higher salt concentrations experienced by Halobacterium salinarum. Moreover, in Haloarchaea, some S-layer glycoproteins are enriched in acidic residues (Eichler, 2003).

The production of halophilic enzymes, such as xylanases, amylases, proteases and lipases has been reported for some halophiles belonging to the genera Acinetobacter, Haloferax, Halobacterium, Halorhabdus, Marinococcus, Micrococcus, Natronococcus, Bacillus, Halobacillus and Halothermothrix (Kumar et al., 2011). Table 4 summarized the dehalogenase bacteria that can withstand halophilic condition. Huang et al. (2011), isolated $\mathrm{DEH} 66, \mathrm{DEH} 99, \mathrm{DEH} 125$ and $\mathrm{DEH} 138$ from the marine sponge Hymeniacidon perlevis for degradation of 2-CP. Seven of the 11 isolates were able to degrade 2-CP at $8 \%$ salt, and four isolates (DEH 66, DEH 99, DEH 125 and DEH 138) degraded $2 \mathrm{CP}$ at $15 \%$ salt. The DEH 66 belongs to Roseobacter sp., DEH 99 was Paracoccus homiensis sp., DEH 125 was Pseudomonas putida sp. and DEH 138 belongs to Pseudomonas stuzeri sp.

Serratia sp. was isolated from soil surrounding lake water located in Universiti Teknologi Malaysia (UTM). Serratia sp. that was cultured in Luria-Bertani (LB) agar 
plates containing $1.0 \%$ sodium chloride $(\mathrm{NaCl})$ has the ability to degrade 2,2-dichloropropionic acid (Abel et al., 2012).

Niknam et al. (2014), isolated new bacteria species which are capable to utilizing 2,2-dichlropropionic acid $(2,2 \mathrm{DCP})$ as a sole carbon source from the wastewater sample that was taken from Tioman Island off the coast of Malaysia. The bacteria that was cultured in 1.0\% sodium chloride $(\mathrm{NaCl})$ was designated as an aerobic bacillus Raoutella ornithilolytica.

Khosrowabadi and Huyop (2014) isolated bacterial from marine sediments collected at Danga Bay and east coast of Singapore. The growth medium was spread on plates containing $20 \mathrm{mM}$ 2,2DCP plus $\mathrm{NaCl}(8 \%)$. The 16S rRNA analysis suggested that the isolated bacteria had more than $96 \%$ sequence identity to the sequence in the NCBI database, therefore, they were designated as Bacillus sp., Rhodococcus sp., Lysinibacillus sp., Microbacterium sp., and Aminobacter sp.

Sufian et al. (2015) isolated bacteria from a marine organism. In this study, a 3CP-degrading bacterium designated as Bacillus sp. strain $\mathrm{H} 4$ was successfully isolated from sponge, Gelliodes sp. that capable of degrading $3 \mathrm{CP}$ as the sole carbon and energy source. The bacteria growth on on solid minimal media containing $10 \mathrm{mM}$ 3CP was the evident for 3CP utilisation.

Edbeib et al. (2016b) presented a study of characterization of Pseudomonas aeruginosa MX1 that can degrade 2,2DCP. Pseudomonas aeruginosa MX1 was isolated from seawater at Desaru, located in the southern coast of Malaysia. There was a high tendency of contamination with halogenated compounds within this stipulated area due to the surrounding agricultural wastewater flow into the sea. The MX1 strain grew best in a $20 \mathrm{mM}$ 2,2DCP minimal medium as the sole carbon source and illustrated a $44 \pm 0.2 \mathrm{~h}$ cell-doubling time as well as a $38 \mathrm{mmol} \mathrm{Cl} / \mathrm{mL}$ maximum rate of chloride ion release. However, no attempt was made to test on the ability to grow in extreme salinity.

\section{RESEARCH PERSPECTIVE}

Several extremophiles microbes with the ability to degrade halogenated compound have been elucidated because of their potential to survive at extreme conditions. It was evident that the use of enzymes isolated from extremophiles offers the prospect to access enzymes that are stable in various conditions such as high temperatures, low temperatures, extreme salt concentration and $\mathrm{pH}$, which can make them more suitable to the industrial environments. Thermophiles, psycrophiles, acidophiles, alkaliphiles and halophiles generally have molecule and membrane stability, produce enzymes or protein and have suitable mechanisms that can survive at extreme conditions. The discovery of new extremophilic species provides a route to new enzymes, with the possibility that this will lead to novel applications. Furthermore, extremophilic enzymes are becoming an essential source of new industrially robust biocatalysts. Nevertheless, this knowledge is still lacking. Only a minor fraction of the microorganisms on earth have been exploited. Thus, the most significant is a current lack of information in basic research, development of appropriate molecular tools as well as looking into a better insight of structure and functions of these extremophile enzymes for biotechnological interest to combat pollution.

\section{REFERENCES}

Aanniz, T., Ouadghiri, M., Melloul, M., Swings, J., Elfahime, E., Ibijbijen, J., Ismaili, M. and Amar, M. (2015). Thermophilic bacteria in Moroccan hot springs, salt marshes and desert soils. Brazilian Journal of Microbiology 46(2), 443-453.

Abel, E., Ibrahim, N. and Huyop, F. (2012). Identification of Serratia marcescens SE1 and determination of its herbicide 2,2- dichloropropionate (2,2-DCP) degradation potential. Malaysian Journal of Microbiology 8, 259-265.

Allpress, J. D. and Gowland, P. C. (1998). Dehalogenases: Environmental defense mechanism and model of enzyme evolution. Biochemical Education 26, 267-276.

Bachas-Daunert, P. G., Law, S. A. and Wei, Y. (2009). Characterization of a recombinant thermostable dehalogenase isolated from the hot spring thermophile Sulfolobus tokodaii. Applied Biochemistry and Biotechnology 159(2), 382-393.

Bakermans, C., Tsapin, A. I., Souza-Egipsy, V., Gilichinsky, D. A. and Nealson, K. H. (2003). Reproduction and metabolism at $-10{ }^{\circ} \mathrm{C}$ of bacteria isolated from Siberian permafrost. Environmental Microbiology 5, 321-326.

Bakermans, C. and Nealson, K. H. (2004). Relationship of critical temperature to macromolecular synthesis and growth yield in Psychrobacter cryopegella. Journal of Bacteriology 186, 2340-2345.

Berger, F., Morellet, N., Menu, F. and Potier, P. (1996). Cold shock and cold acclimation proteins in the psychrotrophic bacterium Arthrobacter globiformis SI55. Journal of Bacteriology 178, 2999-3007.

Chaudhry, G. R. and Chapalamadugu, S. (1991). Biodegradation of halogenated organic compounds. Microbiological Reviews 55(1), 59-79.

Chintalapati, S., Kiran, M. D. and Shivaji, S. (2004). Role of membrane lipid fatty acids in cold adaptation. Cellular and Molecular Biology (Noisy-le-grand) 50, 631-642.

Copley, S. D. (1998). Microbial dehalogenases: Enzymes recruited to convert xenobiotic substrates. Current Opinion in Chemical Biology 2(5), 613-617.

Dalmaso, G. Z. L., Ferreira, D. and Vermelho, A. B. (2015). Marine extremophiles: A source of hydrolases for biotechnological applications. Marine Drugs 13, 1925-1965.

Diez, A., Prieto, M. I., Alvarez, M. J., Bautista, J. M., Puyet, A. and Pertierra, G. (1996). Purification and properties of a high-affinity L-2-haloacid dehalogenase from Azotabacter sp. strain RC26. Letters in Applied Microbiology 23,279-282. 
Donnelly, C. and Murphy, C. D. (2009). Purification and properties of fluoroacetate dehalogenase from Pseudomonas fluorescens DSM 8341. Biotechnology Letters 31(2), 245-250.

Drienovska, I., Chovancova, E., Koudelakova, T., Damborsky, J. and Chaloupkova, R. (2012). Biochemical characterization of a novel haloalkane dehalogenase from a cold-adapted bacterium. Applied and Environmental Microbiology 78, 4995-4998.

Edbeib, M. F. A., Wahab, R. A. and Huyop, F. (2016a). Halophiles: Biology, adaptation, and their role in decontamination of hypersaline environments. World Journal of Microbiology and Biotechnology 32(8), 1-23.

Edbeib, M. F. A., Wahab, R. A. and Huyop, F. (2016b) Characterisation of an $\alpha$-haloalkanoic acid degrading Pseudomonas aeruginosa MX1 isolated from contaminated seawater. Bioremediation Journal 20(2), 89-97.

Eichler, J. (2003). Facing extremes: Archaeal surfacelayer (glyco) proteins. Microbiology 149, 3347-3351.

Gilbert, J. A., Hill, P. J., Dodd, C. E. and LaybournParry, J. (2004). Demonstration of antifreeze protein activity in Antarctic lake bacteria. Microbiology 150, 171-180.

Gilbert, J. A., Davies, P. L. and Laybourn-Parry, J. (2005). A hyperactive, $\mathrm{Ca}^{2+-}$ dependent antifreeze protein in an Antarctic bacterium. FEMS Microbiology Letters 245(1), 67-72.

Godinho, L. M. and de Sá-Nogueira, I. (2011). Characterization and regulation of a bacterial sugar phosphatase of the haloalkanoate dehalogenase superfamily, AraL, from Bacillus subtilis. The FEBS Journal 278(14), 2511-2524.

Hamid, A. A. A., Hamdan, S., Ariffin, S. H. Z. and Huyop, F. (2010). Molecular prediction of dehalogenase producing microorganism using 16S rDNA analysis of 2,2-dichloropropionate (Dalapon) degrading bacterium isolated from volcanic soil. Journal of Biological Sciences 10(3), 190-199.

Hasan, A. K. M. Q., Takada, H., Koshikawa, H., Liu, JQ, Kurihara, T., Esaki, N. and Soda, K. (1994). Two kinds of 2-halo acid dehalogenases from Pseudomonas sp. YL induced by 2-chloroacrylate and 2-chloropropionate. Bioscience, Biotechnology, and Biochemistry 58(9), 1599-1602.

Hasan, K., Fortova, A., Koudelakova, T., Chaloupkova, R., Ishitsuka, M., Nagata, Y., Damborsky, J. and Prokop, Z. (2011). Biochemical characteristics of the novel haloalkane dehalogenase DatA, isolated from the plant pathogen Agrobacterium tumefaciens C58. Applied and Environmental Microbiology 77(5), 18811884.

Horikoshi, K. (1999). Alkaliphiles: Some applications of their products for biotechnology. Microbiology and Molecular Biology Reviews 63,735-750.

Huang, J. Y., Xin, Y. J. and Zhang, W. (2010). Isolation and characterization of haloacid degrading bacteria from marine sponge Hymeniacidon perleve. Fisheries Science 29, 166-171.
Huang, J., Xin, Y., Cao, X. and Zhang, W. (2011). Phylogenetic diversity and characterization of 2haloacid degrading bacteria from the marine sponge Hymeniacidon perlevis. World Journal of Microbiology and Biotechnology 27, 1787-1794.

Hurst, L. D. and Merchant, A. R. (2001). High guaninecytosine content is not an adaptation to high temperature: A comparative analysis amongst prokaryotes. Proceedings of the Royal Society B: Biological Sciences 268, 493-497.

Jesenská, A., Bartos, M., Czerneková, V., Rychlík, I., Pavlík, I. and Damborský, J. (2002). Cloning and expression of the haloalkane dehalogenase gene DhmA from Mycobacterium avium N85 and preliminary characterization of DhmA. Applied Environmental Microbiology 68(8), 3724-3730.

Jia, Z. and Davies, P. L. (2002). Antifreeze proteins: An unusual receptor-ligand interaction. Trends in Biochemical Sciences 27, 101-106.

Jing, N. H. and Huyop, F. (2007). Dehalogenation of chlorinated aliphatic acid by Rhodococcus sp. Asia Pacific Journal of Molecular Biology and Biotechnology 15, 147-151.

Johns, G. C. and Somero, G. N. (2004). Evolutionary convergence in adaptation of proteins to temperature: A4-lactate dehydrogenases of Pacific damselfishes (Chromis spp.). Molecular Biology and Evolution 21, 314-320.

Khosrowabadi, E. and Huyop, F. (2014). Screening and characterization of several 2,2-dicholoropropionic aciddegrading bacteria isolated from marine sediment of Danga Bay and East Coast of Singapore Island. Bioremediation Journal 18, 20-27.

Kumar, L., Awasthi, G. and Singh, B. (2011). Extremophiles: A novel source of industrially important enzymes. Biotechnology 10, 121-135.

Kurihara, T., Esaki, N. and Soda, K. (2000). Bacterial 2haloacid dehalogenases: Structures and reaction mechanisms. Journal of Molecular Catalysis $B$ : Enzymatic 10(1), 57-65.

Li, A. and Shao, Z. (2014). Biochemical characterization of a haloalkane dehalogenase DadB from Alcanivorax dieselolei B-5. PLoS ONE 9(2), 1-9.

Lim, J., Thomas, T. and Cavicchioli, R. (2000). Low temperature regulated DEAD-box RNA helicase from the Antarctic archaeon, Methanococcoides burtonii. Journal of Molecular Biology 297, 553-567.

López-García, P. (2005). Extremophiles. In: Lectures in Astrobiology - Advances in Astrobiology and Biogeophysics. Gargaud M., Barbier, B., Martin H., Reisse J. (eds). Springer, Berlin, Heidelberg. pp. 657679.

Morita, R. Y. (1975). Psychrophilic bacteria. Bacteriological Reviews 39, 144-167.

Muryoi, N., Sato, M., Kaneko, S., Kawahara, H., Obata, H., Yaish, M. W., Griffith, M. and Glick, B. R. (2004). Cloning and expression of $\operatorname{afp} A$, a gene encoding an antifreeze protein from the arctic plant growthpromoting Rhizobacterium Pseudomonas putida GR12-2. Journal of Bacteriology 186, 5661-5671. 
Nichols, M. C. A., Guezennec, J. and Bowman, J. P. (2005). Bacterial exopolysaccharides from extreme marine environments with special consideration of the southern ocean, sea ice, and deep-sea hydrothermal vents: A review. Marine Biotechnology 7, 253-271.

Niknam, M. R., Huyop, F. and Wahab, R. A. (2014). Identification and characterization of Raoutella ornithilolytica and determination of its herbicide 2,2dichloropropionate (2,2-DCP) degradation potential. Malaysian Journal of Microbiology 10, 249-254.

Novak, H. R., Sayer, C., Panning, J. and Littlechild, J. A. (2013a). Characterisation of an L-haloacid dehalogenase from the marine psychrophile Psychromonas ingrahamii with potential industrial application. Marine Biotechnology 15(6), 695-705.

Novak, H. R., Sayer, C., Isupov, M. N., Paszkiewicz, K., DGotz, D., Spragg, A. M. and Littlechild, J. A. (2013b). Marine Rhodobacteraceae L-haloacid dehalogenase contains a novel His/Glu dyad that could activate the catalytic water. The FEBS Journal 280, 1664-1680.

Pandey, K. D., Shukla, S. P., Shukla, P. N., Giri, D. D., Singh, J. S., Singh, P. and Kashyap, A. K. (2004). Cyanobacteria in Antarctica: Ecology, physiology and cold adaptation. Cellular and Molecular Biology (Noisyle-grand) 50, 575-584.

Phadtare, S. (2004). Recent developments in bacterial cold-shock response. Current Issues in Molecular Biology 6, 125-136.

Pikuta, E. V., Hoover, R. B. and Tang, J. (2007). Microbial extremophiles at the limits of life. Critical Reviews in Microbiology 33, 183-209.

Preiss, L., Hicks, D. B., Suzuki, S., Meier, T. and Krulwich, T. A. (2015). Alkaliphilic bacteria with impact on industrial applications, concepts of early life forms, and bioenergetics of ATP synthesis. Frontiers in Bioengineering and Biotechnology 3, 75.

Reed, C. J., Lewis, H., Trejo, E., Winston, V. and Evilia, C. (2013). Protein adaptations in archaeal extremophiles. Archaea 2013, 373275.

Raven, P. H. and Johnson, G. B. (2001). Extremophilic bacteria and microbial diversity. Biology Sixth Edition. The McGraw Hill Companies, United States. pp. 1872.

Riley, M., Staley, J., Danchin, A., Wang, T. Z., Brettin, T., Hauser, L., Miriam, L. and Thompson, L. (2008). Genomics of an extreme psychrophile, Psychromonas ingrahamii. BMC Genomics 9(1), 210.

Roslan, D. D., Gicana, R. G., Lamis, R. J. and Huyop, F. (2011). Characterisation of Bacillus strains from volcanic area Gunung Sibayak able to degrade 2,2dichloropropionic acid. African Journal of Microbiology Research 5(28), 4987-4992.

Russell, N. J. (1997). Psychrophilic bacteria-molecular adaptations of membrane lipids. Comparative Biochemistry and Physiology 118, 489-493.

Rye, C. A., Isupov, M. N., Lebedev, A. A. and Littlechild, J. A. (2009). Biochemical and structural studies of a L-haloacid dehalogenase from the thermophile archeon Sulfolobus tokodaii. Extremophiles 13,179-190.

Sakaff, M. K. L. M., Rahman, A. Y. A., Saito, J. A., Hou, S. B. and Alam, M. (2012). Complete genome sequence of the thermophilic bacterium Geobacillus thermoleovorans CCB US3_UF5. Journal of Bacteriology 194, 1239-1239.

Salim, M. M., Roslan, D. D. and Huyop, F. (2011). Molecular analysis of dehalogenase gene in genomic DNA of Bacillus megaterium strain GS1 isolated from volcanic area Gunung Sibayak. Journal of Biological Sciences 11, 394-398.

Satyanarayana, T., Raghukumar, C. and Shivaji, S. (2005). Extremophilic microbes: Diversity and perspectives. Current Science 89(1), 78-90.

Siglioccolo, A., Paiardini, A., Piscitelli, M. and Pascarella, S. (2011). Structural adaptation of extreme halophilic proteins through decrease of conserved hydrophobic contact surface. BMC Structural Biology 11, 50.

Smith, J. M., Harrison, K., Colby, J. and Taylor, S. C. (1989). Determination of D-2-halopropionate dehalogenase activity from Pseudomonas putida strain AJ1/23 by ion chromatography. FEMS Microbiology Letters 57(1), 71-74.

Smith, J. M., Harrison, K. and Colb, J. (1990). Purification and characterization of D-2-haloacid dehalogenase from Pseudomonas putida strain AJ1/23. Journal of General Microbiology 136(5), 881886.

Sufian, N. H. M., Naim, M. A., Hamid, T. H. T. A., Huyop, F. and Hamid, A. A. A. (2015). Isolation and identification of 3- chloropropionic acid degrading bacterium from marine sponge. Jurnal Teknologi 77(25), 71-75.

Tadeo, X., Lopez-Mendez, B., Trigueros, T., Lain, A., Castano, D. and Millet, O. (2009). Structural basis for the amino acid composition of proteins from halophilic archaea. PLoS Biology 7(12), e1000257.

Thasif, S., Hamdan, S. and Huyop, F. (2009). Degradation of D,L-2-chloropropionic acid by bacterial dehalogenases that shows stereospecificity and its partial enzymatic characteristics. Biotechnology 8(2), 264-269.

van den Burg, B. (2003). Extremophiles as a source for novel enzymes. Current Opinion in Microbiology 6(8), 213-218.

Xu, Y., Nogi, Y., Kato, C., Liang, Z., Ruger, H. J., De Kegel, D. and Glansdorff, N. (2003). Moritella profunda sp. nov. and Moritella abyssi sp. nov., two psychropiezophilic organisms isolated from deep Atlantic sediments. International Journal of Systematic and Evolutionary Microbiology 53, 533-538.

Zhang, J., Xin, Y., Cao, X., Xue, S. and Zhang, W. (2014). Purification and characterization of 2-haloacid dehalogenase from marine bacterium Paracoccus sp. DEH99, isolated from marine sponge Hymeniacidon perlevis. Journal of Ocean University of China 13(1), 91-96. 